\title{
Chip-based ion chromatography (chip-IC) with a sensitive five-electrode conductivity detector for the simultaneous detection of multiple ions in drinking water
}

\author{
Xiaoping Li (10 ${ }^{1}$ and Honglong Chang (10
}

\begin{abstract}
The emerging need for accurate, efficient, inexpensive, and multiparameter monitoring of water quality has led to interest in the miniaturization of benchtop chromatography systems. This paper reports a chip-based ion chromatography (chip-IC) system in which the microvalves, sample channel, packed column, and conductivity detector are all integrated on a polymethylmethacrylate (PMMA) chip. A laser-based bonding technique was developed to guarantee simultaneous robust sealing between the homogeneous and heterogeneous interfaces. A five-electrode-based conductivity detector was presented to improve the sensitivity for nonsuppressed anion detection. Common anions $\left(\mathrm{F}^{-}, \mathrm{Cl}^{-}, \mathrm{NO}_{3}{ }^{-}\right.$, and $\left.\mathrm{SO}_{4}{ }^{2-}\right)$ were separated in less than $8 \mathrm{~min}$, and a detection limit (LOD) of $0.6 \mathrm{mg} \mathrm{L}^{-1}$ was achieved for $\mathrm{SO}_{4}{ }^{2-}$. Tap water was also analyzed using the proposed chip-IC system, and the relative deviations of the quantified concentration were less than $10 \%$ when compared with that a commercial IC system.
\end{abstract}

\section{Introduction}

Safe drinking water is a critical resource for human health $^{1,2}$. Among a variety of contaminants, some chemical species present an ongoing concern ${ }^{3}$. For example, an epidemiological study has shown that long-term exposure to fluoride and nitrate in drinking water can lead to chronic diseases ${ }^{4}$. In addition, chloride and sulfate may cause certain aesthetic effects. Therefore, the allowed concentrations of these species in drinking water have been regulated worldwide (Table 1). It is of great health significance for end-users to measure the concerned ions accurately, inexpensively, and conveniently.

Although the foregoing anions can be measured on-site by using simple commercial test kits based on color reactions on specific strips (Table S1 and Fig. S1), only

Correspondence: Honglong Chang (changhl@nwpu.edu.cn)

${ }^{1}$ Ministry of Education Key Laboratory of Micro/Nano Systems for Aerospace, School of Mechanical Engineering, Northwestern Polytechnical University,

710072 Xi'an, P. R. China qualitative results can be obtained, and only a single element can be detected in one test. In contrast, anions can be quantitatively and simultaneously determined in a laboratory by ion chromatography (IC) ${ }^{5}$, which is considered the standard method for detecting common cations and anions in water samples. Unfortunately, current chromatography systems are too bulky for use in field tests $^{6,7}$. In past decades, advancements in lab-on-a-chip technology have successfully addressed this issue for both chip-based gas chromatography (chip-GC) $)^{8-11}$ and chipbased liquid chromatography (chip-LC) ${ }^{12-15}$ but relatively less so for chip-IC. Kidd et al. ${ }^{16}$ packed a silicon microchannel with anion resin to test common anions by incorporating an external syringe pump, injector, and contactless conductivity detector $\left(C^{4} D\right)$. Tanaka et al. ${ }^{17}$ presented a polymethylmethacrylate (PMMA) chip packed with anion exchangers to detect glycated hemoglobin $\left(\mathrm{HbA}_{1 \mathrm{c}}\right)$. However, the chip was also operated by a commercial syringe pump, valve, and electrochemical

\section{(c) The Author(s) 2020}

(c) (i) Open Access This article is licensed under a Creative Commons Attribution 4.0 International License, which permits use, sharing, adaptation, distribution and reproduction cc) in any medium or format, as long as you give appropriate credit to the original author(s) and the source, provide a link to the Creative Commons license, and indicate if changes were made. The images or other third party material in this article are included in the article's Creative Commons license, unless indicated otherwise in a credit line to the material. If material is not included in the article's Creative Commons license and your intended use is not permitted by statutory regulation or exceeds the permitted use, you will need to obtain permission directly from the copyright holder. To view a copy of this license, visit http://creativecommons.org/licenses/by/4.0/. 
Table 1 Maximum contaminant levels (MCLs, in $\mathrm{mg} \mathrm{L}^{-1}$ ) for concerned anions according to drinking water quality standards by the World Health Organization (WHO), European Union (EU), United States of America (USA), and China

\begin{tabular}{lllll}
\hline & WHO & EU & USA & China \\
\hline Fluoride $\left(\mathrm{F}^{-}\right)$ & 1.5 & 1.5 & 4.0 & 1.0 \\
Nitrate $\left(\mathrm{NO}_{3}{ }^{-}\right)$ & 50 & 50 & $10($ as N) & $10($ as N) \\
Chloride $\left(\mathrm{Cl}^{-}\right)$ & - & 250 & 250 & 250 \\
Sulfate $\left(\mathrm{SO}_{4}{ }^{2-}\right)$ & - & 250 & 250 & 250 \\
\hline
\end{tabular}

Dash (-) indicates that Guideline values have not been established ${ }^{a} 10 \mathrm{mg} \mathrm{L}^{-1}\left(\mathrm{NO}_{3}{ }^{-}\right.$as $\left.\mathrm{N}\right) \approx 44.3 \mathrm{mg} \mathrm{L}^{-1}\left(\mathrm{NO}_{3}^{-}\right)$

detector. Previously, our group also reported a packed PMMA IC chip for the detection of $\mathrm{HbA}_{1 \mathrm{c}}{ }^{18}$. Ultraviolet-visible spectroscopy (UV/Vis) detection was performed through a fiber-coupled microspectrometer. Despite these advances, developing a compact anionoriented chip-IC is still a challenge. On the one hand, the current chip-IC mainly relies on discrete commercial parts, and the level of integration needs to be further improved. On the other hand, a lightweight but sensitive on-chip detector for anions should also be developed.

Basically, the primary parts of a chip-IC system comprise a micropump, injector, column, and detector. Considering that band broadening only occurs at the flow path between the sample injection channel, column, and detection cell ${ }^{12}$, the integration of a micropump is nonessential, and a traditional LC pump or syringe pump can still be used for chip-IC. Nevertheless, an integrated micropump can dramatically reduce the size and weight of the whole system ${ }^{19}$.

The column is the most important part of an IC system. Though on-chip columns have been achieved in opentubular $^{20,21}$, monolithic ${ }^{22,23}$, and pillar array ${ }^{24,25}$ forms, it is straightforward to pack the channel with commercially available resins, and better reproducibility can be guaranteed because no surface modification of the particulates is needed ${ }^{26}$. To keep beads in the channels, frit structures with feature sizes smaller than the resin's diameter are usually needed. However, commonly used frits, such as weirs ${ }^{27}$, step-shaped channels ${ }^{28}$, and parallel small channels ${ }^{29}$, follow a similar multistep lithography and etching process, and interfacial bonding is also severely challenged by the high-pressure resistance of the packed bed. Therefore, more attention should be given to both the chip material and corresponding fabrication. For example, the commonly used polydimethylsiloxane (PDMS) in microfluidics is limited in chip-LC because PDMS is gas permeable and the bonding strength is relatively poor ${ }^{30}$.

Sample injection on-chip has been mainly achieved by using T-shaped ${ }^{31,32}$ or cross-shaped ${ }^{27,33}$ channels.
However, external valves are needed for fluid on/off control at the sample inlet and outlet. In contrast, integrated microvalves are urgently desired ${ }^{34}$, but their implementation is restricted by the high working pressure $^{35}$ or until the poor bonding strength of the heterogeneous interface between the substrate and valve membrane is improved.

Ultrasensitive detectors, such as mass spectrometry $(\mathrm{MS})^{22,28,29,36}$ and laser-induced fluorescence (LIF) ${ }^{20,21,23}$, have been widely used in chip-LC to measure biomolecules, organic compounds, and pharmaceuticals. However, conductivity detection (CD) is the first choice for IC due to its universality to ionic samples ${ }^{37}$. In macro-IC systems, a suppressor is commonly used to neutralize the high background conductivity of the eluent before $C D$ to increase the detection sensitivity. Although a suppressor on-chip system has recently been reported ${ }^{38}$, the integration of suppressors in a chip-IC system is much more complicated; therefore, nonsuppressed $\mathrm{CD}$, which uses a low-conductivity eluent for direct CD after separation, is more suitable for chip-IC. In terms of the detector cell, electrodes can be either in direct contact or not with the eluate. Although the contact mode can provide higher sensitivity than the contactless model ${ }^{39}$, the electrode reaction may lead to large baseline noise and thus compromise the signal-to-noise ratio $(\mathrm{S} / \mathrm{N})$ and sensitivity. Therefore, a contact $\mathrm{CD}$ with steady and reduced baseline noise is helpful to increase the sensitivity in nonsuppressed chip-IC.

Herein, we developed a compact chip-IC system for the detection of anions in drinking water. A channel network with various cavities was micromilled in one step on a PMMA substrate. Commercial sintered frits and valve membrane disks were embedded into the corresponding cavities for integration. Both homogeneous and heterogeneous interfaces were robustly sealed by laser bonding to resist the high working pressure. A conductivity detector with a five-electrode configuration was integrated to improve the $\mathrm{S} / \mathrm{N}$ in the nonsuppressed mode. Separation of both anion standards and tap water was demonstrated by using the proposed chip-IC system.

\section{Results and discussion Chip-IC system}

Figure 1a presents an overview of the experimental setup. The chip-IC system consists of an IC chip as well as necessary electronics including a data processing circuit and a data acquisition (DAQ) unit, and it is arranged in a 3D-printed box that is $17 \times 19 \times 10 \mathrm{~cm}^{3}$ in size and less than $2 \mathrm{~kg}$ in weight. A conventional pump is connected to the chip through PEEK fitting (Agilent, Beijing, China) for eluent delivery. The chromatographic signal is read from the DAQ and recorded on a computer. For chromatographic separation, the IC chip (Fig. 1b) uses the sample 


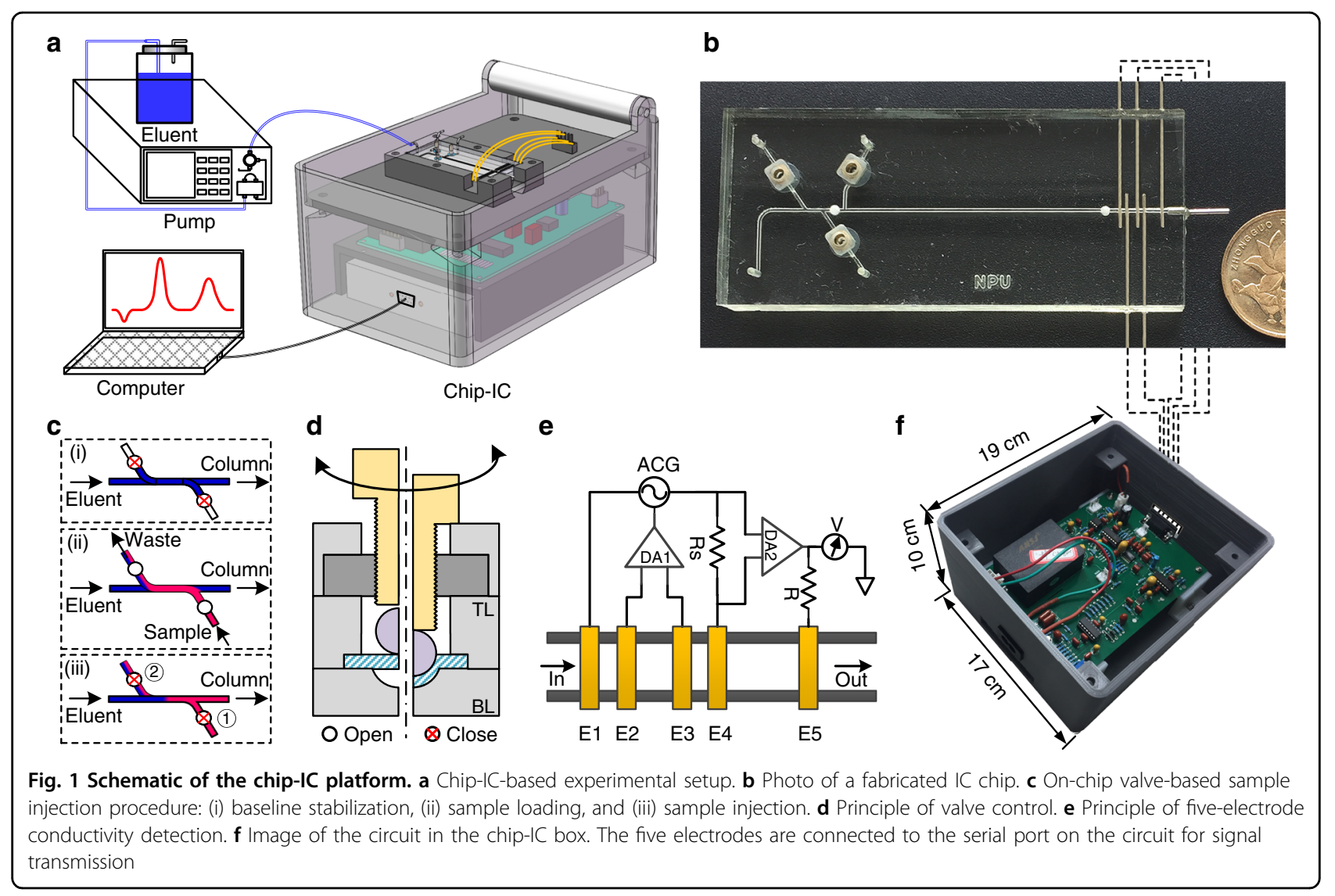

injection procedure shown in Fig. 1c. Briefly, the packed channel is first equilibrated using the eluent to obtain a steady baseline. The two valves are then opened, and the sample is injected from the inlet. After injection, the two valves are closed sequentially, and the sample plug will be drawn into the packed channel for separation. All valves are currently driven by screw $^{40,41}$ (Fig. 1d); however, micromotors or solenoid valves can also be incorporated for automated control ${ }^{40}$. To obtain an exact on/off operation under high pressure, a tiny ball is adopted to force the membrane to be in close contact with the hemispheric valve chamber.

Figure 1e shows the principle of the five-electrode $C D$ system. The five electrodes include the two reference electrodes (E1 and E4), two detection electrodes (E2 and E3), and an electrical ground electrode (E5). A sinusoidal current is applied to E1 and E4 (denoted as $\mathrm{I}_{14}$ ) and is controlled by a variable AC generator (ACG). E2 and E3 are inputs to a differential amplifier (DA1). When the conductance between E2 and E3 $\left(G_{23}\right)$ changes, the output of DA1 will force the ACG to vary $\mathrm{I}_{14}$ to maintain a constant potential drop between E2 and E3 $\left(\mathrm{U}_{23}\right)$. In response, the potential drop on the sampling resistor $\left(\mathrm{U}_{\mathrm{Rs}}\right)$ will also vary and be further converted by another differential amplifier (DA2) and finally detected by voltmeter V. E5 reduces the capacitance leakage to the ground. Because there is only a very low current at E2 and E3, common problems in contact mode, such as Faradaic impedance, are largely eliminated. Therefore, the $5 \mathrm{e}$ detector will give a more stable baseline and accurate measurement of the solution conductance, which makes it very suitable for nonsuppressed IC detection ${ }^{42}$. A developed PCB for signal processing is presented in Fig. 1f.

\section{Chip fabrication}

The device is fabricated by combining micromilling and laser bonding techniques. The process (Fig. 2a) mainly involves three steps: (1) single-layered chips with various channel geometries are micromilled ${ }^{43}$; (2) small chips are cleaned, and a pair of pieces as well as frits, valve membranes, and electrodes are assembled together; and (3) the assembled block is laser-bonded (Fig. S2).

From the infrared view (Fluke Ti400, Beijing, China) of laser bonding (Fig. 2b), only a small local zone of PMMA is heated to high temperature and melts (Fig. 2c). The PMMA melts can slightly flow into any interfacial gaps, and after resolidification, effective sealing is achieved on both the homogeneous PMMA interface and heterogeneous interfaces, e.g., PMMA/frit, PMMA/valve membrane, and PMMA/electrode (Fig. 2d, e). The normal 


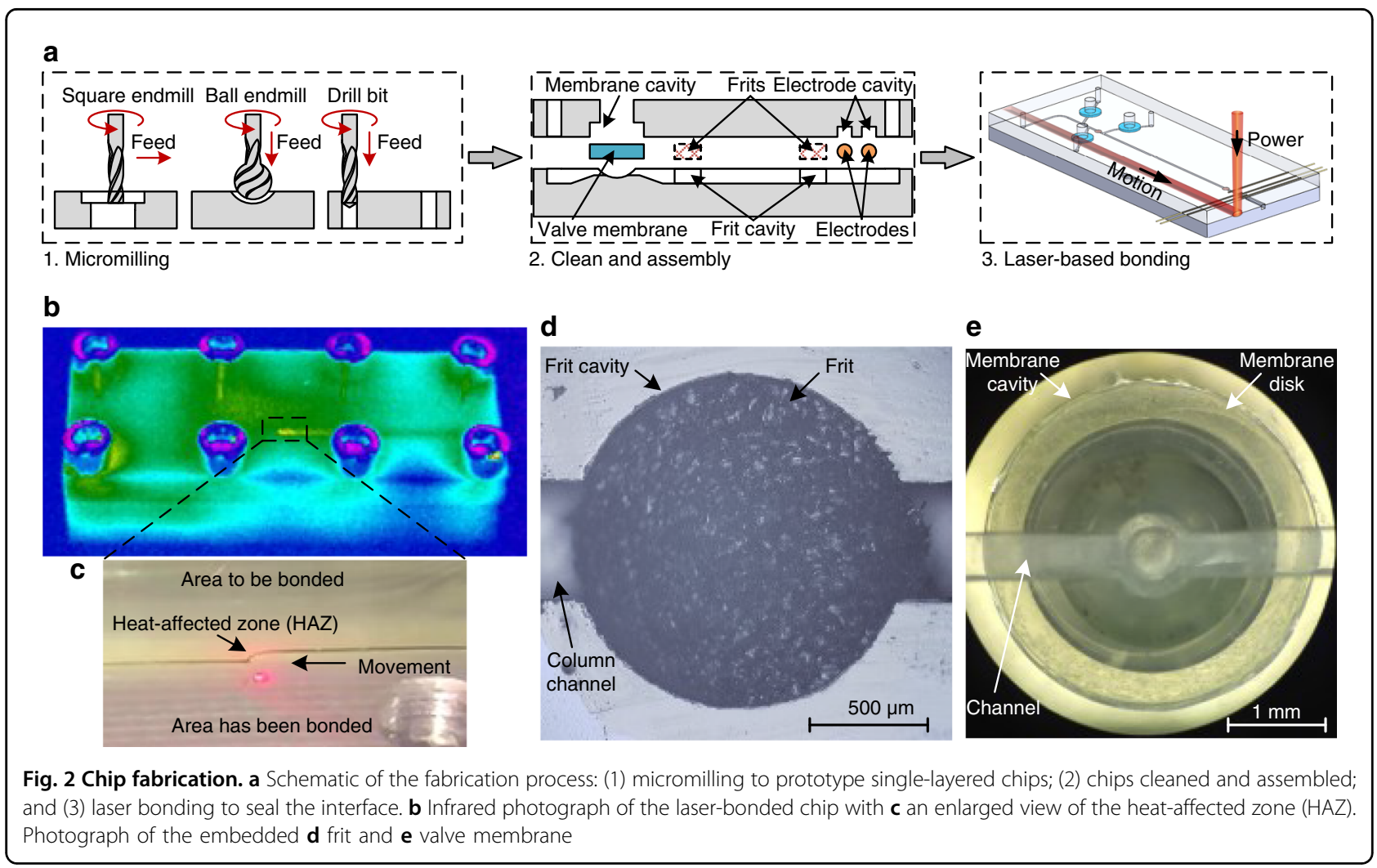

stress of bonded chips was measured using a tensile tester (SFMIT, Suzhou, China). Dumbbell-shaped specimens with a $1.5 \times 2 \mathrm{~mm}^{2}$ cross-section were tested at a pull rate of $1.0 \mathrm{~mm} \mathrm{~min}^{-1}$ (Fig. S3). Most (6 of 8) of the specimens were fractured out of the bonded interface, and the average normal strength was calculated to be $74.5 \mathrm{MPa}$, with a relative standard deviation (RSD) of $0.64 \%(n=8)$. This value is much larger than that reported by $\mathrm{Hsu}$ et al. ${ }^{44}(17.6 \mathrm{MPa})$ and Tran et al. ${ }^{45}(6.17 \mathrm{MPa})$. Sealing between heterogeneous interfaces was tested by using the burst pressure method (Fig. S4). A burst pressure of 10.6 $\mathrm{MPa}$ was recorded with leakage occurring at the world-to-chip connection rather than the chip interface. This value is also much higher than that reported by Hsu et al. ${ }^{44}(0.69 \mathrm{MPa})$ and is sufficient for column packing and chromatographic separation.

\section{Column packing quality}

The chip was packed using a slurry method (Fig. S5). The dimensionless flow resistance $\phi$ gives a comparative measure of the packing quality of a column, which is defined as ${ }^{46}$

$$
\frac{\phi}{\varepsilon}=\frac{d_{\mathrm{p}}^{2} A_{\mathrm{c}}}{\eta L_{\mathrm{c}}} \frac{\Delta p}{F}
$$

where $\varepsilon$ is the porosity of the column (typically $\sim 0.65$ ), $\Delta p$ is the pressure drop of the column, $d_{\mathrm{p}}$ is the bead diameter,

$A_{\mathrm{c}}$ is the column cross-sectional area, $L_{\mathrm{c}}$ is the column length, and $\eta$ and $F$ are the viscosity and flow rate of the mobile phase, respectively. Generally, $\phi$ is $500-1000$ for packed columns, and a lower value usually indicates poor packing with voids or cracks. Figure 3 shows the pressure drop at varying flow rates of DI water, where $\phi$ is calculated to be 650 . This value is well within the typical range of 500-1000, meaning that a favorable packed quality was achieved. In addition, according to the $\phi$ value of 355 with assumed $\varepsilon=0.8$ obtained in a parylene channel packed with 
the same beads used here ${ }^{46}, \phi$ is calculated to be 289 with $\varepsilon=0.65$. The higher $\phi$ values here also mean that better packing quality was achieved by following the current column design and packing technique.

\section{Detection of anion standards}

A set of $\mathrm{SO}_{4}{ }^{2-}$ standard solutions with concentrations of $\left\{5,10,25,50\right.$, and $\left.100 \mathrm{mg} \mathrm{L}^{-1}\right\}$ were tested at a flow rate of $25 \mu \mathrm{L} \mathrm{min}^{-1}$, with each concentration tested three times. As shown in Fig. 4, good linearity $\left(R^{2}=0.996\right)$ was observed in the range of $5-100 \mathrm{mg} \mathrm{L}^{-1}$ for the 5 e detector. The RSDs of the retention time $t_{\mathrm{R}}$ and peak height $H$ are $0.2-0.5 \%$ and $0.6-2.4 \%$, respectively. Based on the observed $\mathrm{S} / \mathrm{N}$ at $5 \mathrm{mg} \mathrm{L}^{-1}$, the $\mathrm{S} / \mathrm{N}=3 \mathrm{LOD}$ is calculated to be $0.6 \mathrm{mg} \mathrm{L}^{-1}$.

Two standard mixtures, i.e., (\#1, 10-20-20) containing $10 \mathrm{mg} \mathrm{L}^{-1} \mathrm{Cl}^{-}, 20 \mathrm{mg} \mathrm{L}^{-1} \mathrm{NO}_{3}{ }^{-}$, and $20 \mathrm{mg} \mathrm{L}^{-1} \mathrm{SO}_{4}{ }^{2-}$ and (\#2, 50-10-30-20) containing $50 \mathrm{mg} \mathrm{L}^{-1} \mathrm{~F}^{-}, 10 \mathrm{mg}$ $\mathrm{L}^{-1} \mathrm{Cl}^{-}, 30 \mathrm{mg} \mathrm{L}^{-1} \mathrm{NO}_{3}{ }^{-}$, and $20 \mathrm{mg} \mathrm{L}^{-1} \mathrm{SO}_{4}{ }^{2-}$, were tested using the packed chip at a flow rate of $25 \mu \mathrm{L} \mathrm{min}^{-1}$. As shown in Fig. $5 \mathrm{a}, \mathrm{F}^{-}$and $\mathrm{Cl}^{-}$overlap under the current

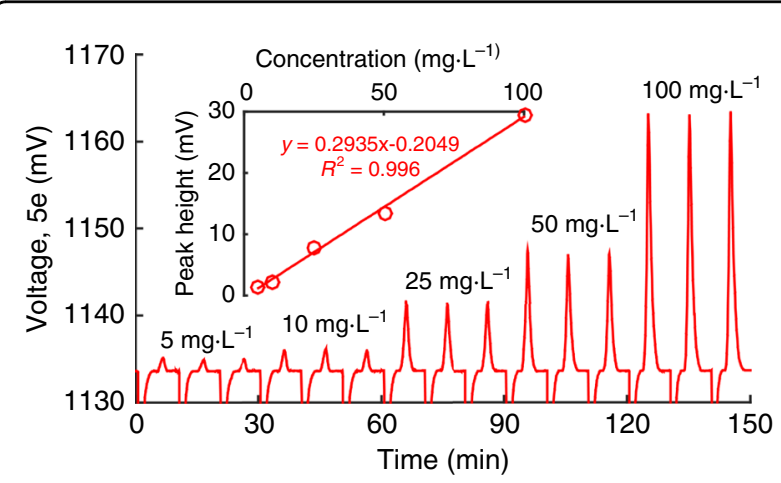

Fig. 4 Chromatograms of $\mathrm{SO}_{4}{ }^{2-}$ standards tested at a flow rate of $25 \mu \mathrm{L} \min ^{-1}(n=3)$. The inset shows the calibration plot. Eluent: 4-mM p-HBA containing $2.5 \%$ methanol $(\mathrm{pH}=8.5)$. Injection: $0.5 \mu \mathrm{L}$. Detection: ambient chip and conditions. This overlap may be due to the large water dip in nonsuppressed IC, which has been confirmed in nonsuppressed capillary $\mathrm{ICs}^{47}$. However, the overlapping peaks of $\mathrm{F}^{-}$and $\mathrm{Cl}^{-}$can be discriminated by postprocessing in software such as OriginPro (Fig. S6). On the other hand, it is very promising to separate $\mathrm{F}^{-}$and $\mathrm{Cl}^{-}$ directly by using more advanced and smaller resins and optimizing the buffer condition.

The three-anion mixture $(\# 1,10-20-20)$ was tested at varying flow rates. Figure $5 \mathrm{~b}$ shows that the smaller flow rate achieves better resolution, although the analysis time is longer. At a flow rate of $25 \mu \mathrm{L} \mathrm{min}^{-1}$, all three ions can be detected within $8 \mathrm{~min}$. The separation efficiency, namely, the number of theoretical plates, is defined as $N$ $=5.54\left(t_{\mathrm{R}} / W_{\mathrm{h} / 2}\right)^{2}$, where $t_{\mathrm{R}}$ is the retention time and $W_{\mathrm{h} / 2}$ is the full width at half maximum (FWHM). As the flow rate varies from $25 \mu \mathrm{L} \mathrm{min}^{-1}$ to $10 \mu \mathrm{L} \mathrm{min}{ }^{-1}$, the $N$ values (plates $\mathrm{m}^{-1}$ ) for $\mathrm{Cl}^{-}, \mathrm{NO}_{3}{ }^{-}$, and $\mathrm{SO}_{4}{ }^{2-}$ are $3800-7100$, 7100-11,200, and 6100-9600, respectively (Table S3). Compared with nonsuppressed $\mathrm{CapIC}^{47}$, chip-IC showed better efficiency in the separation of relatively strongly retained $\mathrm{NO}_{3}{ }^{-}$(reported $N=5400$ ); nevertheless, the $N$ value of $\mathrm{Cl}^{-}$in chip-IC is only half that reported $(N=$ 15,800 ) in CapIC. The large difference in relatively weakly retained species may also be attributed to the large water dip in the nonsuppressed IC.

\section{Detection of tap water}

Tap water was successfully analyzed using the chip-IC system at room temperature. A water sample was collected directly from the tap, filtered, and then injected for separation. Separation tests were performed at 7 am and 7 pm. Figure 6 and Table 2 show the obtained chromatograms and corresponding concentrations of anions, respectively. Water samples were also tested on a benchtop IC system (IC-8286, Luhai Photoelectric, Qingdao, China), which confirmed that only $\mathrm{F}^{-} \mathrm{Cl}^{-}$,
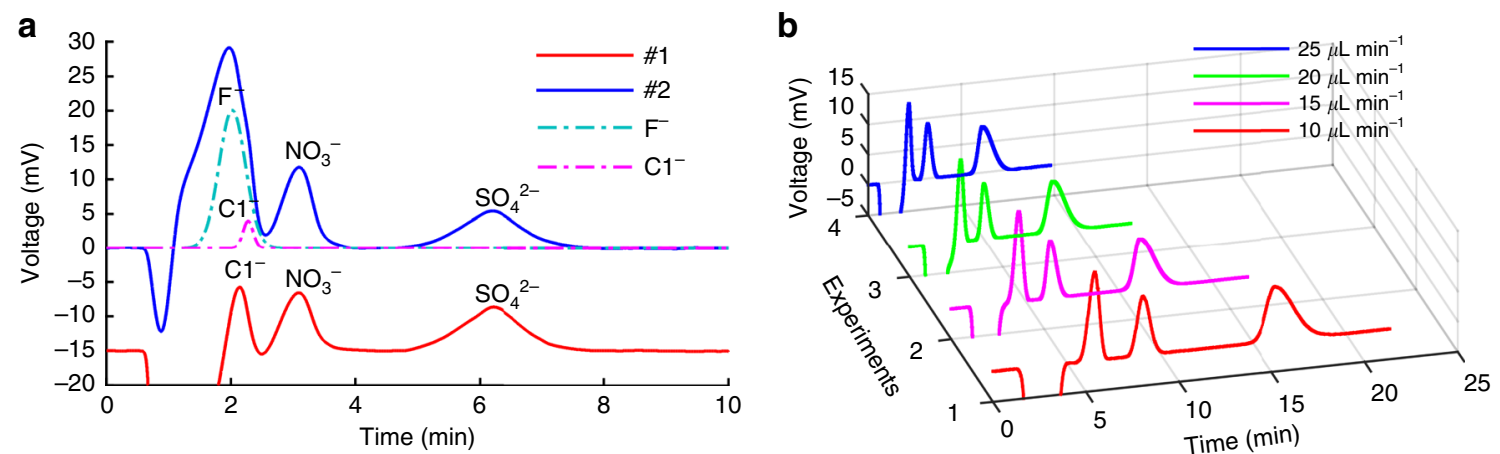

Fig. 5 Chromatograms of standard mixtures. a Mixture \#1 (10-20-20) and mixture \#2 (50-10-30-20) both tested at a flow rate of $25 \mu \mathrm{L} \mathrm{min}^{-1}$ b Mixture \#1 (10-20-20) tested at varying flow rates. Dashed lines in a represent peaks of $\mathrm{F}^{-}$and $\mathrm{Cl}^{-}$discriminated from the overlapping curve of mixture \#2. Other conditions are the same as in Fig. 4 


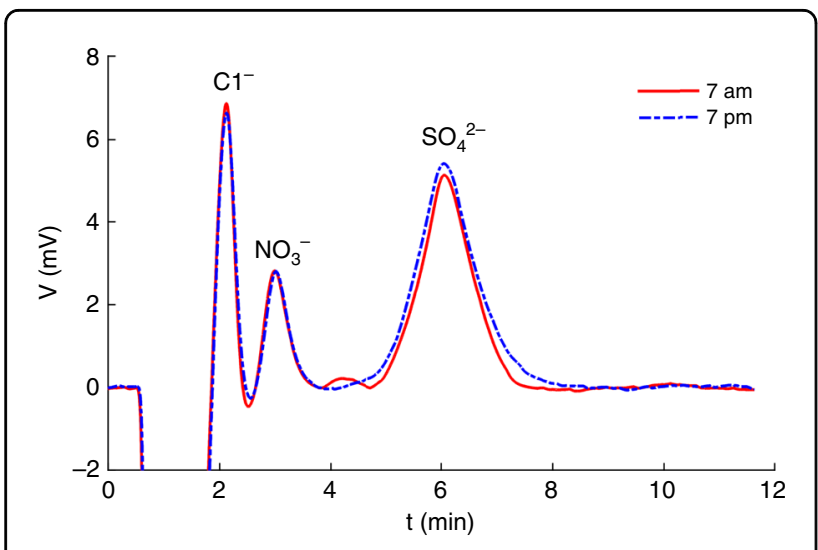

Fig. 6 Chromatograms of anions in tap water detected by chip-IC. The conditions are the same as in Fig. 4

$\mathrm{NO}_{3}{ }^{-}$, and $\mathrm{SO}_{4}{ }^{2-}$ were determined. Therefore, no other overlap occurs on the chromatograph by chip-IC except for $\mathrm{F}^{-}$and $\mathrm{Cl}^{-}$. As mentioned, the overlapping $\mathrm{F}^{-}$and $\mathrm{Cl}^{-}$peaks can be post-treated for peak discrimination. However, the concentration of $\mathrm{F}^{-}$is so small that the postprocessing would result in a large relative error. To assess the true detectability of the chip-IC system, only $\mathrm{NO}_{3}{ }^{-}$and $\mathrm{SO}_{4}{ }^{2-}$ data by chip-IC are quantified and presented in Table 2, which reveals that the relative deviations of concentrations of these anions obtained by chip-IC are less than 10\% when compared with the commercial IC-8286 system.

\section{Materials and methods Reagents}

Isopropanol, methanol, $p$-hydroxybenzoic acid ( $p$-HBA), sodium chloride, sodium hydroxide, anion stock solutions $\left(1000 \mathrm{mg} \mathrm{L}^{-1}\right)$ of fluoride $\left(\mathrm{F}^{-}\right)$, chloride $\left(\mathrm{Cl}^{-}\right)$, nitrate $\left(\mathrm{NO}_{3}{ }^{-}\right)$, and sulfate $\left(\mathrm{SO}_{4}{ }^{2-}\right)$, and two standard mixturesone containing $10 \mathrm{mg} \mathrm{L}^{-1} \mathrm{Cl}^{-}, 20 \mathrm{mg} \mathrm{L}^{-1} \mathrm{NO}_{3}{ }^{-}$, and $20 \mathrm{mg} \mathrm{L}^{-1} \mathrm{SO}_{4}{ }^{2-}$ (\#1, 10-20-20), and the other containing $50 \mathrm{mg} \mathrm{L}^{-1} \mathrm{~F}^{-}, 10 \mathrm{mg} \mathrm{L}^{-1} \mathrm{Cl}^{-}, 30 \mathrm{mg} \mathrm{L}^{-1} \mathrm{NO}_{3}^{-}$, and $20 \mathrm{mg} \mathrm{L}^{-1} \mathrm{SO}_{4}{ }^{2-}(\# 2,50-10-30-20)$ - were all acquired from Sigma-Aldrich (Shanghai, China) at reagent grade. Single-anion calibration standards were prepared by diluting the stock solution with deionized water to the desired concentration. The eluent was prepared in $4.0 \mathrm{mM}$ $p$-HBA solution containing $2.5 \%$ methanol, with the $\mathrm{pH}$ adjusted to 8.5 by $0.1 \mathrm{M} \mathrm{NaOH}$. All solutions were filtered using a $0.2 \mu \mathrm{m}$ filter before use.

\section{Chip design and fabrication}

The device was designed using SolidWorks (Dassault Systemes, Waltham, MA, USA). The whole chip consists of two layers: the bottom layer (BL) containing the microchannel network including a double-T sample injection junction, valve chamber, frit cavities, separation
Table 2 Comparison of detected concentrations of anions in tap water by Chip-IC and IC-8286 (mg L $\left.{ }^{-1}\right)$

\begin{tabular}{lllllll}
\hline Species & $\mathbf{7}$ am & \multicolumn{5}{c}{$\mathbf{7}$ pm } \\
\cline { 2 - 3 } \cline { 6 - 7 } \cline { 6 - 7 } & Chip-IC & IC-8286 & $\begin{array}{l}\text { Relative } \\
\text { deviation }\end{array}$ & $\begin{array}{c}\text { Chip-IC } \\
\text { IC-8286 }\end{array}$ & $\begin{array}{l}\text { Relative } \\
\text { deviation }\end{array}$ \\
\hline $\mathrm{F}^{-}$ & - & 0.71 & & - & 0.77 & \\
$\mathrm{Cl}^{-}$ & - & 5.4 & & - & 5.8 & \\
$\mathrm{NO}_{3}{ }^{-}{ }^{-} \mathrm{N}$ & 4.7 & 4.3 & $9.3 \%$ & 4.6 & 4.4 & $4.5 \%$ \\
$\mathrm{SO}_{4}{ }^{2-}$ & 17.1 & 16.6 & $3.0 \%$ & 20.1 & 19.6 & $2.6 \%$ \\
\hline
\end{tabular}

column, and detection cell and the top layer (TL) containing the valve membrane cavities, electrode cavities and through vias for valve control and tube connection. The cross-sectional size of the channel is $500 \times 500 \mu \mathrm{m}^{2}$. A $0.5 \mu \mathrm{L}$ sample plug is defined by a double-T-shaped side channel at a distance of $2 \mathrm{~mm}$. The separation channel is $40 \mathrm{~mm}$ long. Two frit cavities are set at each side of the separation channel, and the depth and diameter of each frit cavity are $0.5 \mathrm{~mm}$ and $1.4 \mathrm{~mm}$, respectively. The diameter of commercially available ultrahigh-molecular weight polyethylene (UHMW-PE) frits (Biocomma, Shenzhen, China) is also $1.4 \mathrm{~mm}$. Another side channel is set to introduce the slurry for chip packing. Every side channel has a membrane microvalve integrated for fluid on/off manipulation. The diameter and depth of the spherical valve chamber are $0.5 \mathrm{~mm}$ and $0.6 \mathrm{~mm}$, respectively. The depth and diameter of valve membrane cavities are $4 \mathrm{~mm}$ and $0.5 \mathrm{~mm}$, respectively; 4-mm-diameter disks are cut from a $500-\mu \mathrm{m}$-thick highly elastic silicone sheet (Sanhe 3A Rubber \& Plastic Co., Hebei, China) to function as valve membranes. The diameters of the through vias for valve control and tube connection are $1 \mathrm{~mm}$ and $3 \mathrm{~mm}$, respectively. The total chip size is $30 \times 70 \mathrm{~mm}^{2}$.

Additionally, 3-mm-thick PMMA sheets (Evonik Röhm, Darmstadt, Germany) are micromilled to create channels and then cut into pieces using a $\mathrm{CNC}$ machine (Jingdiao, Beijing, China). Small pieces are ultrasonically cleaned in isopropanol for $2 \mathrm{~min}$, rinsed in DI water, dried with nitrogen, and then laser-bonded at room temperature. Briefly, the Clearweld ${ }^{\mathrm{TM}}$ absorber (CrystaLyn, Binghamton, NY, USA) is first manually coated on the top surface of the BL. Then, the frits and membrane disks are inserted into the frit cavities and membrane cavities. Pt wires $0.5 \mathrm{~mm}$ in diameter are inserted into the electrode channels. Then, a pair of chips are stacked, clamped using a homemade fixture, and laser-bonded. The focused spot is $\sim 400 \mu \mathrm{m}$, and the optimal laser power, scanning velocity and pitch are $10 \mathrm{~W}, 8 \mathrm{~mm} \mathrm{~s}^{-1}$, and $0.4 \mathrm{~mm}$, respectively. 


\section{Column packing}

An approximately $80 \mathrm{mg} \mathrm{mL}^{-1}$ slurry of $7 \mu \mathrm{m}$ PRPX110 anion exchanger (Hamilton Reno, NV, USA) is prepared in a $2 \mathrm{M} \mathrm{NaCl}$ solution and ultrasonicated for $1 \mathrm{~min}$. A PEEK tube $(0.5 \mathrm{~mm}$ i.d. and $10 \mathrm{~cm}$ long $)$ filled with slurry is connected between the packing inlet and an HPLC pump (Hanbon Sci. \& Tech., Huai'an, China). The channel is packed at a flow rate of $200 \mu \mathrm{L} \mathrm{min}{ }^{-1}$, which is ten times larger than that for separation. The frit has an average pore size of $2 \mu \mathrm{m}$ and, thus, can keep the beads within the channel. The maximum pumping pressure is set to $10 \mathrm{MPa}$, at which point the pump will turn off automatically, the packing valve will close, and the packed channel will depressurize spontaneously.

\section{Conclusions}

In this paper, a high-pressure-compatible ion chromatography chip was fabricated by using micromilling and laser-based bonding methods. Owing to the melting-resolidification transition, high bonding strength has been achieved. Using the integrated fiveelectrode conductivity detector, standard anion solutions and tap water were successfully analyzed. Although cations have not yet been tested, theoretically, better results can be obtained using the same system. With further improvements in micropump integration and automated valve control, we believe that a fully portable chip-IC device would be an alternative tool for field environmental testing, especially for high-throughput detection in water.

\section{Acknowledgements}

We acknowledge the financial support from the Shaanxi Key Research and Development Program (Grant No. 2019ZDLGY02-06 \& Grant No. 2016KTCQ0148), the Fundamental Research Funds for the Central Universities (Grant No. 3102019J(002).

\section{Author contributions}

H.C. proposed the idea and supervised the study. X.L. performed the chip design, fabrication, and the experiments. All authors discussed and approved the manuscript.

\section{Conflict of interest}

The authors declare that they have no conflict of interest.

Supplementary information accompanies this paper at https://doi.org/ 10.1038/s41378-020-0175-x.

Received: 30 December 2019 Revised: 25 March 2020 Accepted: 26 April 2020

Published online: 24 August 2020

\footnotetext{
References

1. Landrigan, P. J. et al. The Lancet Commission on pollution and health. Lancet 391, 462-512 (2018).

2. Allaire, M., Wu, H. \& Lall, U. National trends in drinking water quality violations. Proc. Natl Acad. Sci. USA 115, 2078-2083 (2018).
}

3. Levallois, P. \& Villanueva, C. Drinking water quality and human health: an editorial. Int. J. Environ. Res. Public Health 16(4pp), 631 (2019).

4. Villanueva, C. M. et al. Assessing exposure and health consequences of chemicals in drinking water: current state of knowledge and research needs. Environ. Health Perspect. 122, 213-221 (2014).

5. Michalski, R. Ion chromatography applications in wastewater analysis. Separations $\mathbf{5}$ (12pp), 16 (2018).

6. Zulkifli, S. N., Rahim, H. A. \& Lau, W.-J. Detection of contaminants in water supply: a review on state-of-the-art monitoring technologies and their applications. Sens. Actuators B Chem. 255, 2657-2689 (2018).

7. Jang, A., Zou, Z., Lee, K. K., Ahn, C. H. \& Bishop, P. L. State-of-the-art lab chip sensors for environmental water monitoring. Meas. Sci. Technol. 22(18pp), 032001 (2011).

8. Wang, J. et al. Compact prototype microfabricated gas chromatographic analyzer for autonomous determinations of VOC mixtures at typical workplace concentrations. Microsyst. Nanoeng. 4(10pp), 17101 (2018).

9. Zhou, M.-D. et al. Chopper-modulated gas chromatography electroantennography enabled using high-temperature MEMS flow control device. Microsyst. Nanoeng. 3(10pp), 17062 (2017).

10. Qin, Y. \& Gianchandani, Y. B. A fully electronic microfabricated gas chromatograph with complementary capacitive detectors for indoor pollutants. Microsyst. Nanoeng. 2(11pp), 15049 (2016).

11. Akbar, M., Restaino, M. \& Agah, M. Chip-scale gas chromatography: from injection through detection. Microsyst. Nanoeng. 1(8pp), 15039 (2015).

12. Haghighi, F., Talebpour, Z. \& Nezhad, A. S. Towards fully integrated liquid chromatography on a chip: evolution and evaluation. Trends Anal. Chem. 105, 302-337 (2018).

13. Yuan, X. \& Oleschuk, R. D. Advances in microchip liquid chromatography. Anal. Chem. 90, 283-301 (2018).

14. Grinias, J. P. \& Kennedy, R. T. Advances in and prospects of microchip liquid chromatography. Trends Anal. Chem. 81, 110-117 (2016).

15. Desmet, G. \& Eeltink, S. Fundamentals for LC miniaturization. Anal. Chem. $\mathbf{8 5}$, 543-556 (2013).

16. Kidd, R. D. et al. Ion Chromatography-on-a-Chip for Water Quality Analysis. In Proc. 45th Internationaal Conference on Environmental Systems (ICES 2015), 141 (8pp), (Bellevue, 2015).

17. Tanaka, T. et al. On-chip type cation-exchange chromatography with ferrocene-labeled anti-hemoglobin antibody and electrochemical detector for determination of hemoglobin A1c level. Anal. Chim. Acta 638, 186-190 (2009).

18. Li, D. Li, X. \& Chang, H. An integrated ion chromatography microchip for ultra fast measurement of glycated hemoglobin levels. in Proc. IEEE MEMS 2018, pp 1189-1192. (Belfast, 2018).

19. Li, X., Li, D., Liu, X. \& Chang, H. Ultra-monodisperse droplet formation using PMMA microchannels integrated with low-pulsation electrolysis micropumps. Sens. Actuators B Chem. 229, 466-475 (2016).

20. Smirnova, A., Shimizu, H., Pihosh, Y., Mawatari, K. \& Kitamori, T. On-chip stepmixing in a T-nanomixer for liquid chromatography in extendednanochannels. Anal. Chem. 88, 10059-10064 (2016).

21. Fuentes, H. V. \& Woolley, A. T. Electrically actuated, pressure-driven liquid chromatography separations in microfabricated devices. Lab Chip 7, 1524-1531 (2007).

22. Dietze, C., Hackl, C., Gerhardt, R., Seim, S. \& Belder, D. Chip-based electrochromatography coupled to ESI-MS detection. Electrophoresis 37, 1345-1352 (2016).

23. Ladner, Y. et al. New 'one-step' method for the simultaneous synthesis and anchoring of organic monolith inside COC microchip channels. Lab Chip 12, 1680-1685 (2012).

24. Isokawa, M. et al. Liquid chromatography chip with low-dispersion and lowpressure-drop turn structure utilizing a distribution-controlled pillar array. Anal. Chem. 88, 6485-6491 (2016).

25. Callewaert, M. et al. Integration of uniform porous shell layers in very long pillar array columns using electrochemical anodization for liquid chromatography. Analyst 139, 618-625 (2014).

26. Kutter, J. P. Liquid phase chromatography on microchips. J. Chromatogr. A 1221, 72-82 (2012).

27. Thurmann, S., Dittmar, A. \& Belder, D. A low pressure on-chip injection strategy for high-performance chip-based chromatography. J. Chromatogr. A 1340 59-67 (2014). 
28. Xie, J., Miao, Y., Shih, J., Tai, Y. C. \& Lee, T. D. Microfluidic platform for liquid chromatography-tandem mass spectrometry analyses of complex peptide mixtures. Anal. Chem. 77, 6947-6953 (2005).

29. Lazar, I. M. \& Kabulski, J. L. Microfluidic LC device with orthogonal sample extraction for on-chip MALDI-MS detection. Lab Chip 13, 2055-2065 (2013).

30. Li, X., Chang, H., Liu, X., Ye, F. \& Yuan, W. A 3-D overbridge-shaped micromixer for fast mixing over a wide range of Reynolds numbers. J. Microelectromech. Syst. 24, 1391-1399 (2015).

31. De Malsche, W. et al. Pressure-driven reverse-phase liquid chromatography separations in ordered nonporous pillar array columns. Anal. Chem. 79, 5915-5926 (2007).

32. Liu, J. et al. Polymer microchips integrating solid-phase extraction and highperformance liquid chromatography using reversed-phase polymethacrylate monoliths. Anal. Chem. 81, 2545-2554 (2009).

33. Schlund, M., Gilbert, S. E., Schnydrig, S. \& Renaud, P. Continuous sampling and analysis by on-chip liquid/solid chromatography. Sens. Actuators B Chem. 123, 1133-1141 (2007)

34. Lavrik, N. V., Taylor, L. C. \& Sepaniak, M. J. Enclosed pillar arrays integrated on a fluidic platform for on-chip separations and analysis. Lab Chip 10, 1086-1094 (2010).

35. Li, Y. et al. Miniaturised electrically actuated high pressure injection valve for portable capillary liquid chromatography. Talanta 180, 32-35 (2018).

36. Heiland, J. J. et al. On-chip integration of organic synthesis and HPLC/MS analysis for monitoring stereoselective transformations at the micro-scale. Lab Chip 17, 76-81 (2017).

37. Yang, B., Zhang, M., Kanyanee, T., Stamos, B. N. \& Dasgupta, P. K. An open tubular ion chromatograph. Anal. Chem. 86, 11554-11561 (2014).
38. Wouters, S., Bruggink, C., Agroskin, Y., Pohl, C. \& Eeltink, S. Microfluidic membrane suppressor module design and evaluation for capillary ion chromatography. J. Chromatogr. A 1484, 26-33 (2017).

39. Coltro, W. K. T. et al. Capacitively coupled contactless conductivity detection on microfluidic systems - ten years of development. Anal. Methods 4, 25-33 (2012).

40. Elizabeth Hulme, S., Shevkoplyas, S. S. \& Whitesides, G. M. Incorporation of prefabricated screw, pneumatic, and solenoid valves into microfluidic devices. Lab Chip 9, 79-86 (2009).

41. Chen, C. F., Liu, J., Chang, C. C. \& DeVoe, D. L. High-pressure on-chip mechanical valves for thermoplastic microfluidic devices. Lab Chip 9 3511-3516 (2009).

42. Haddad, P. R. \& Jackson, P. E. in Journal of Chromatography Library Volume 46, 245-289 (Elsevier, 1990).

43. Guckenberger, D. J., de Groot, T. E., Wan, A. M. D., Beebe, D. J. \& Young, E. W. K Micromilling: a method for ultra-rapid prototyping of plastic microfluidic devices. Lab Chip 15, 2364-2378 (2015).

44. Hsu, Y.-C. \& Chen, T.-Y. Applying Taguchi methods for solvent-assisted PMMA bonding technique for static and dynamic $\mu$-TAS devices. Biomed. Microdevices 9, 513-522 (2007).

45. Tran, H. H., Wu, W. \& Lee, N. Y. Ethanol and UV-assisted instantaneous bonding of PMMA assemblies and tuning in bonding reversibility. Sens. Actuators $B$ Chem. 181, 955-962 (2013).

46. He, Q., Pang, C., Tai, Y.-C. \& Lee, T. D. Ion liquid chromatography on-a-chip with beads-packed parylene column. In Proc. IEEE MEMS 2004, pp 212-215, (Maastricht, 2004).

47. Huang, W. \& Dasgupta, P. K. Electrodialytic capillary suppressor for open tubular ion chromatography. Anal. Chem. 88, 12021-12027 (2016). 